\title{
Non-linearity and Expectations in Niche-Development Trajectories: Ups and Downs in Dutch Biogas Development (1973-2003)
}

\author{
FRANK GEELS \& ROB RAVEN \\ Eindhoven University of Technology, The Netherlands
}

\begin{abstract}
Non-linearity and changes in the direction of technological trajectories, are related to changes in cognitive rules and expectations that guide technical search and development activities. To explain such changes, the article uses the literature on niche development, which highlights interactions between learning processes, network building and expectations. A long-term case study on Dutch biogas development illustrates how these interactions explain non-linearity, but the case study also shows the importance of external regime dynamics. It is concluded that nonlinearity and changes in niche expectations are related to both internal learning processes and external developments.
\end{abstract}

\section{Introduction}

This article deals with non-linearity in long-term development trajectories of new technologies. Non-linearity refers to changes in the direction of such trajectories. Technological trajectories are stable patterns in technological development that exist at the global level of a community of actors. Evolutionary economists ${ }^{1}$ argue that when cognitive routines (such as search heuristics, exemplars, guiding principles) become shared within a community, they orient perceptions and actions of actors in local practices. Because technical search activities in different locations are focused in a similar direction, they add up to a technical trajectory. Sociologists of technology also highlight the importance 'technological frames' with cognitive rules such as goals, problem agendas, problem-solving strategies, current theories, tacit knowledge, design methods and criteria. ${ }^{2}$ These cognitive rules represent stocks of accumulated knowledge from previous experiences, guiding perception and interpretation. Expectations and visions are a special set of cognitive rules that are oriented to the future and related to action, in the sense that they give direction to search and development activities. Expectations about future technological performance cannot be

Correspondence Address: Frank Geels, Eindhoven University of Technology, IPO 2.10, PO Box 513, 5600 MB Eindhoven, The Netherlands; Tel. +31-(0)40-247-5414; Fax +31-(0)40-244-4602. E-mail: f.w.geels@tm.tue.nl 
checked independently, but only through actions that make them come true. Expectations, visions and beliefs have the dynamic of self-fulfilling prophecies, because they guide R\&D activities that work towards realising them. Hence expectations function as 'prospective structures to be filled in with agency' ${ }^{3}$ So 'a technological trajectory can be seen as a self-fulfilling prophecy. Patterns of technological change are persistent, because technologists and others believe they will be persistent' [our emphasis]. ${ }^{4}$ If we accept that shared cognitive rules and expectations create stable trajectories, then a change in direction, i.e. non-linearity, depends on a change in the content of cognitive rules and expectations.

This leads to a subsequent question: how do cognitive rules and expectations change in innovation journeys? To answer that question, this article makes additions to Van Lente's semiotic perspective on the role of expectations in technological development. ${ }^{5}$ When a new technological opportunity emerges, generated externally or from previous work, its protagonists formulate promises about future performance and functionality to attract attention from sponsors. If these promises are accepted, they are translated into a shared expectation or agenda for an emerging field. The expectation is then translated into goals, specifications, requirements and task divisions, for which projects are developed. Sponsors make money and other resources available for these projects, thus creating a protected space where search and development activities may take place. When the projects end, usually after a couple of years, outcomes are assessed and new promises are formulated. The result is a 'promise-requirement cycle' (Figure 1), that forms part of the underlying dynamics of long-term innovation journeys.

An under-developed aspect in this perspective is the link from protected space to opportunity and new promise. In our view, there is not enough attention for learning processes in protected spaces and how they help change the content of expectations and cognitive rules. An improved understanding on that point is necessary to explain non-linearity. To that end, we will use the literature on strategic niche management (SNM) to make additions to the expectations literature. ${ }^{6}$ Although SNM has a policy-oriented dimension, it is based on an analytical core that conceptualises the emergence of new technologies.

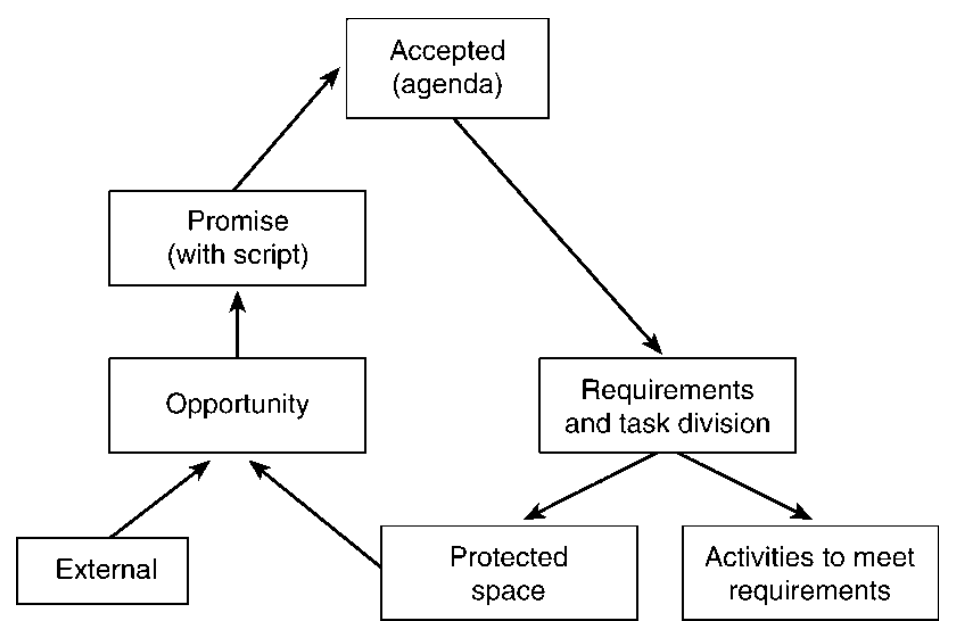

Figure 1. Promise-requirement conversion Source: Van Lente (Ref. 5, p. 199). 
The article is structured as follows. The next section elaborates on SNM and presents a perspective on niche development trajectories, conceptualising interactions between learning processes, expectations and social networks. This perspective is then illustrated with a case study of manure digestion and biogas plants in the Netherlands (19732003). The article concludes that non-linearity in this case can be partly explained with the niche development perspective. Because external regime dynamics are also found to be crucial, an addition to this perspective is made, using Van Lente's notion of nested expectations.

\section{The Dynamics of Niche Development Trajectories}

When new technologies emerge, their performance is initially low, costs are high, there is uncertainty about precise form and function, and there is no stable network to support them. Hence, new technologies cannot immediately compete with existing technological regimes that are characterised by lock-in and path dependence. The starting point of SNM is that new technologies emerge in 'protected spaces', which shield them from mainstream market selection. Using an ecological/evolutionary metaphor, such protected spaces form 'niches' for radical novelties. Niches may have the form of small market niches, where selection criteria are different from the existing regime. Or they may have the form of technological niches, where resources are provided by public subsidies or strategic company investments. Once the development in niches results in robust technologies with better price/performance ratio, they can enter mainstream markets.

The SNM approach conceptualises experimental projects, pilot projects and demonstration projects with new technologies as important phase between R\&D and market diffusion. In evolutionary terms, such experimental projects provide interaction between variation and selection-environment, allowing users, policy makers and special-interest groups to give feedback to technology developers (firms, engineers and researchers). So, experimental projects provide space for interactions between actors and the building of social networks. Local projects also provide space for learning and articulation processes with regard to technical design, user preferences, regulation, infrastructure requirements, cultural meaning. These learning processes are both about knowledge development and about the alignment of heterogeneous elements into a working technical configuration (artefact-on-location). Building on the expectations literature, ${ }^{7}$ SNM scholars highlighted a third process: the articulation of expectations and visions. Expectations are important to attract attention and resources from other actors, and expectations provide direction to learning processes and technical development activities.

In early SNM work, the focus was often on individual projects, using these three nicheinternal processes to explain success and failure. Reasons for failure could be: expectations were insufficiently clear, leading to divergence between actors involved; the local project network was fragmented and not broad enough; learning processes were focused too narrowly on technical aspects. ${ }^{8}$

Recent work, especially several PhD theses, ${ }^{9}$ has expanded the analytical core of SNM in three ways. One addition is to distinguish between concrete local projects and a global niche-level, carried by an emerging field or community (Figure 2).

This local-global distinction has been used by other authors to emphasise particular aspects. Law and Callon distinguished between local and global networks in their analysis of an aircraft development project. ${ }^{10}$ The local network consists of actors who work on the 


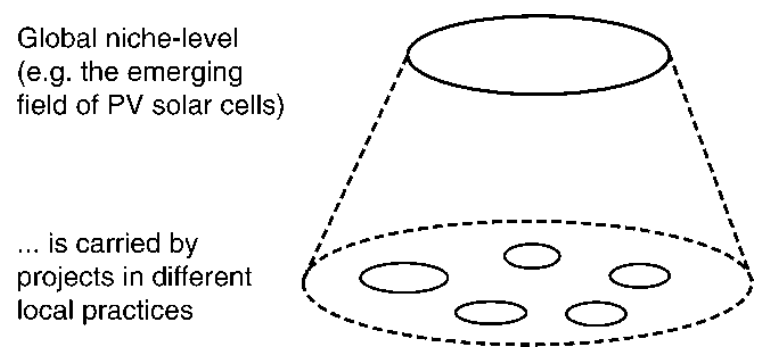

Figure 2. Local projects and global niche-level

project, and develop and align heterogeneous bits and pieces on location. The global network consists of actors who have some distance to the project, but are related through providing resources, such as finance, political support, technical specifications, that generate a space in which local actors can work. Given our focus on multiple projects, we somewhat rephrase this distinction: local networks refers to actors who are directly involved in projects, while the global network refers to an emerging field or community.

Hård, Disco, Van der Meulen and Deuten highlighted another aspect, namely local knowledge with variability (skills, hands-on-experiences) and global, abstract, generic knowledge that is shared within a community. ${ }^{11}$ The latter are cognitive rules in the form of knowledge products (abstract theories, technical models, formulas) or in the form of frames that structure learning processes (problem agendas, search heuristics, guiding principles, rules of thumb, exemplars). Global cognitive rules form resources and guiding frames for activities in local practices, but leave room for local interpretations and adjustments. So there can be variety in local practices, depending on specific local networks and project definitions, as well as a degree of stability at the global level, in the form of cognitive rules shared in an emerging community.

Together both aspects of the local-global distinction provide a socio-cognitive perspective. Especially at the local level, there is space to incorporate the artefact dimension of technology and bricolage activities to make 'configurations that work', something that, as we know from actor-network theory, requires the alignment of heterogeneous resources such as practical knowledge, tacit skills, tools, machines, money and people. So, this may be characterised as a techno-socio-cognitive perspective. ${ }^{12}$

A second addition is that recent SNM work changed the focus from individual to multiple projects. These projects can exist simultaneously and build on each other over time. Sequences of local projects can gradually add up to a technological trajectory at the global level (Figure 3). In this process, global niche rules and expectations, that are initially diffuse, broad and unstable, become more articulated, specific and stable.

The transformation of local outcomes into generic lessons and cognitive rules does not occur automatically, but requires dedicated 'aggregation activities' ${ }^{13}$ Typical aggregation activities include standardization, codification, model building, formulation of best practices, etc. Also circulation of knowledge and actors is important, to enable comparison between local practices and formulation of generic lessons: conferences, workshops, technical journals, proceedings, newsletters play a role here.

Third, recent SNM work shifted the focus to interactions between the three nicheinternal processes (learning and articulation processes, building of social networks, articulation of expectations) and how this results in innovation journeys. Actors, embedded in 


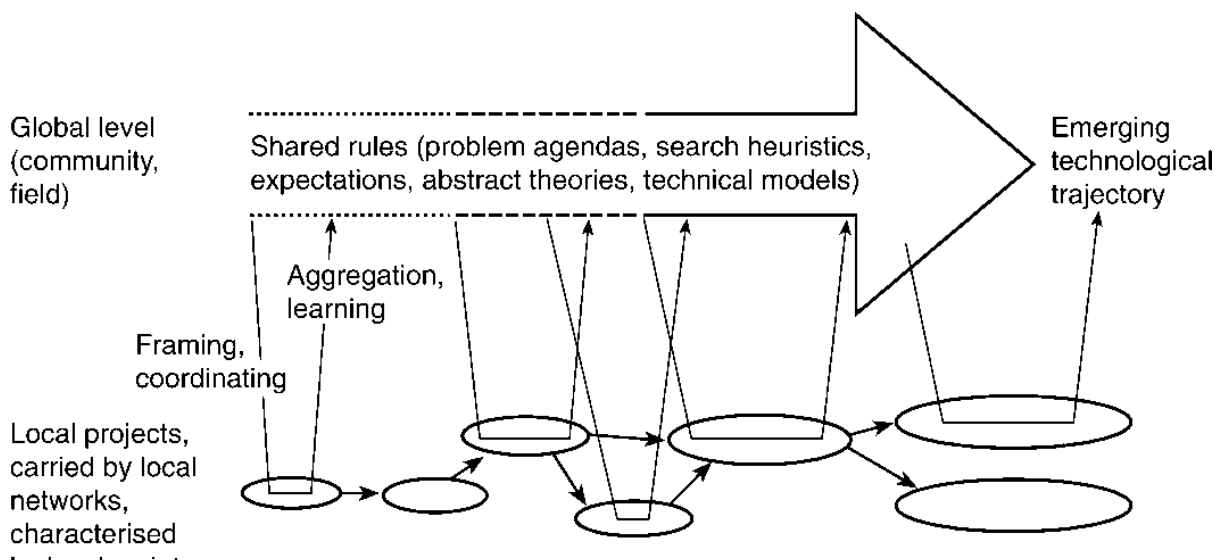

Figure 3. Technical trajectory carried by local projects

networks, are willing to invest resources (money, people) in projects, if they have a shared, positive expectation of a new technology. This shared expectation, together with shared cognitive rules, also provides direction to the projects. Projects, carried by local networks, provide space for local activities. The outcomes give rise to learning processes that may be aggregated into generic lessons and rules. Outcomes are also used to adjust previous expectations and enrol more actors to expand the social network (see Figure 4). ${ }^{14}$

These interacting processes form the underlying dynamic of niche-development trajectories, giving a symmetrical explanation of linearity and non-linearity in technological

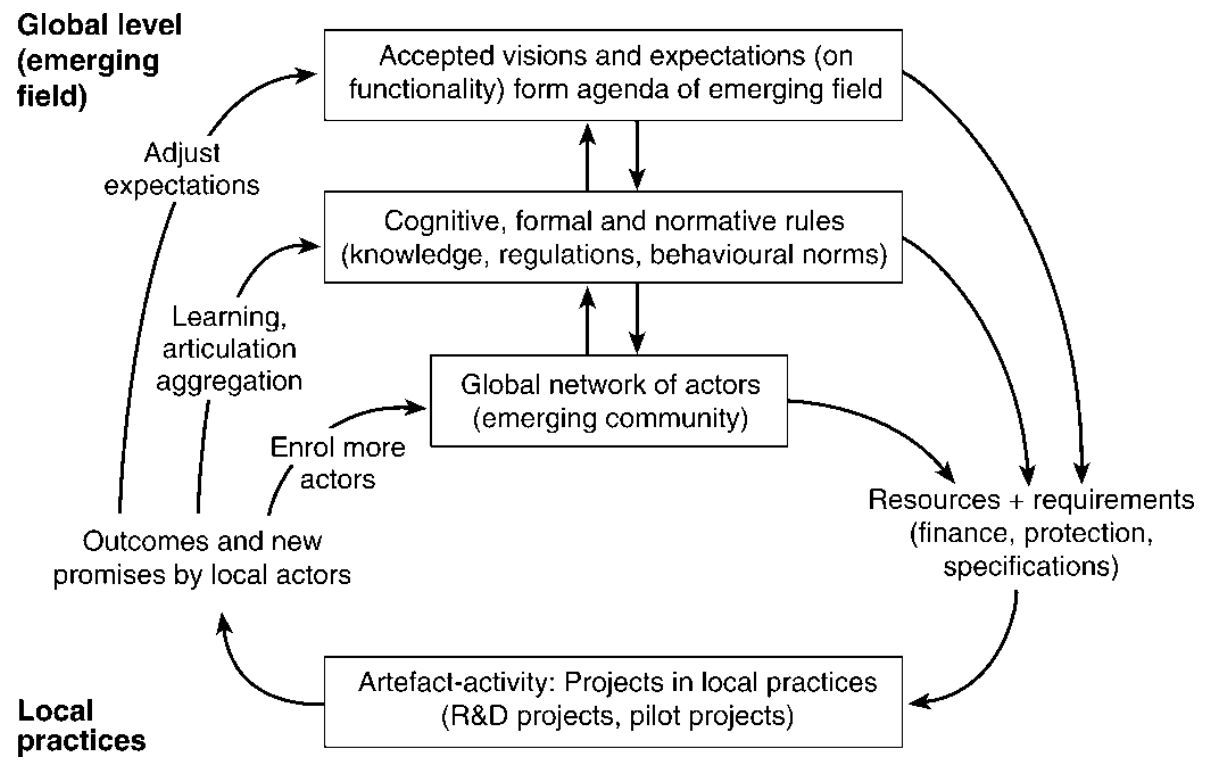

Figure 4. The dynamics of niche development trajectories 
trajectories. The main point is that change and stability in cognitive rules and expectations depend on interactions with learning processes and network building.

If outcomes of learning processes are positive (i.e. the initial expectation is validated and accepted as promising for further work) a new development cycle is initiated that enables further refinement within the shared rules. Technical models, problem agendas and search heuristics can be made more specific, parameters can be refined, and user preferences may become more articulated. Such developments down the design hierarchy, ${ }^{15}$ give rise to incremental adjustments along trajectories. The cognitive frame and expectations remain stable, but become more detailed and refined. Positive outcomes also make it easier to enrol new actors and expand the social network, resulting in more resources for new projects.

If outcomes are much below expectation, faith in the new technology diminishes and expectations decline, followed by shrinking social networks and drying up of resources. In response to these negative outcomes, actors tend to engage in repair work and come up with new expectations that promise better results for search heuristics in other directions. If these redirected promises find their way into the agenda of the field, then non-linearity occurs and the innovation journey changes course.

\section{Case Study: Ups and Downs in Dutch Biogas Plant Developments}

This section builds heavily on Raven's PhD thesis. ${ }^{16}$ Data have been collected from various heterogeneous sources including policy documents, research reports, scientific journals, conference proceedings, minutes and slides from meetings, newspapers, and interviews with involved actors. The niche development perspective will be illustrated with a case study of Dutch manure digestion and the production of biogas, a mixture of methane and carbon dioxide. Central in a biogas plant is the anaerobic digester where microbes convert part of the manure into biogas (Figure 5). The addition of organic waste sources (e.g. fish oil, corn) may increase biogas yields, something that was discovered gradually. Before manure enters the digester, it might be pre-processed for hygienic reasons. Biogas is one end product of digestion, which can be used to generate heat and power. Before use, biogas contaminations need to be removed (especially corrosive hydrogen sulphide). The second product is processed manure that can be used as fertilizer.

Dutch development of biogas plants shows ups and downs. Figures 6 and 7 respectively show the number of plants and the cumulative installed digester capacity. In the late 1970s and early 1980s about 27 small farmscale plants were implemented, processing manure

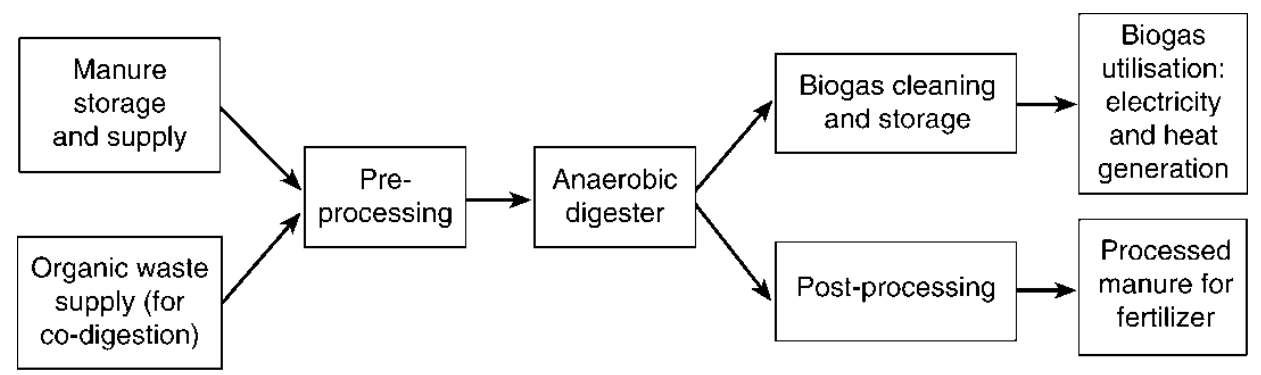

Figure 5. Basic layout of a biogas plant 


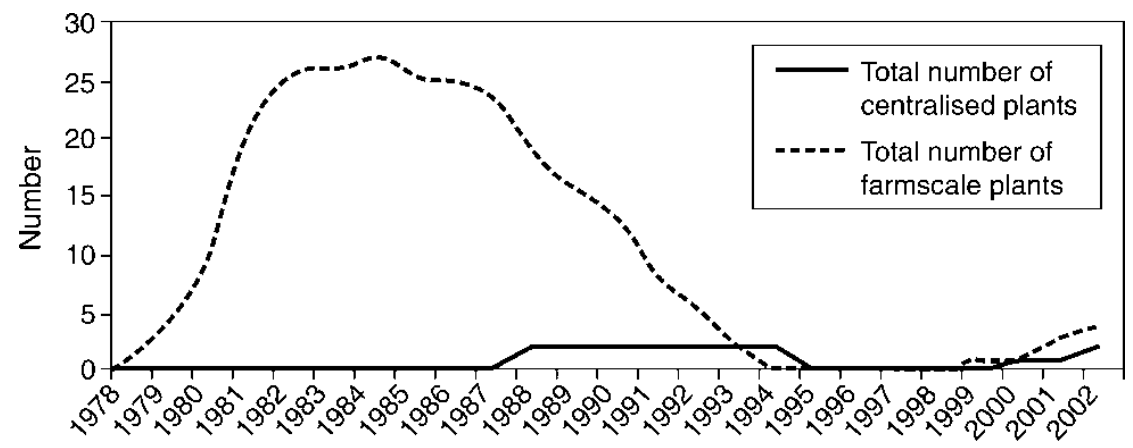

Figure 6. Accumulated number of Dutch farmscale and centralised biogas plants. Source: Based on data in Raven (Ref. 9).

from a single farm. Biogas was used on-site to heat stables, while processed manure was used on the land. Between 1986 and 1995 the number of farmscale plants steadily declined and dropped to zero. In the mid-1980s attention shifted towards large centralised biogas plants, which processed manure from multiple farms and were operated by dedicated firms, often with chemical competencies. Two centralised plants were constructed, one of them with huge processing capacity. Both plants were shut down in 1995. Between 1995 and 1998 no plants existed. In 1999 both farmscale and centralised plants re-emerged. These non-linear developments are analysed in the following three subsections.

\section{The Rise of Farmscale Plants (1975-1985)}

Farmers faced high energy prices in the 1970s and 1980s following two oil crises. Hence, researchers at Wageningen Agricultural University thought that energy generation from manure looked promising. Although fundamentals of digestion were known scientifically, there was no practical design knowledge. Technology suppliers had general agricultural knowledge (e.g. construction of silos), but no experience with biogas plants. No

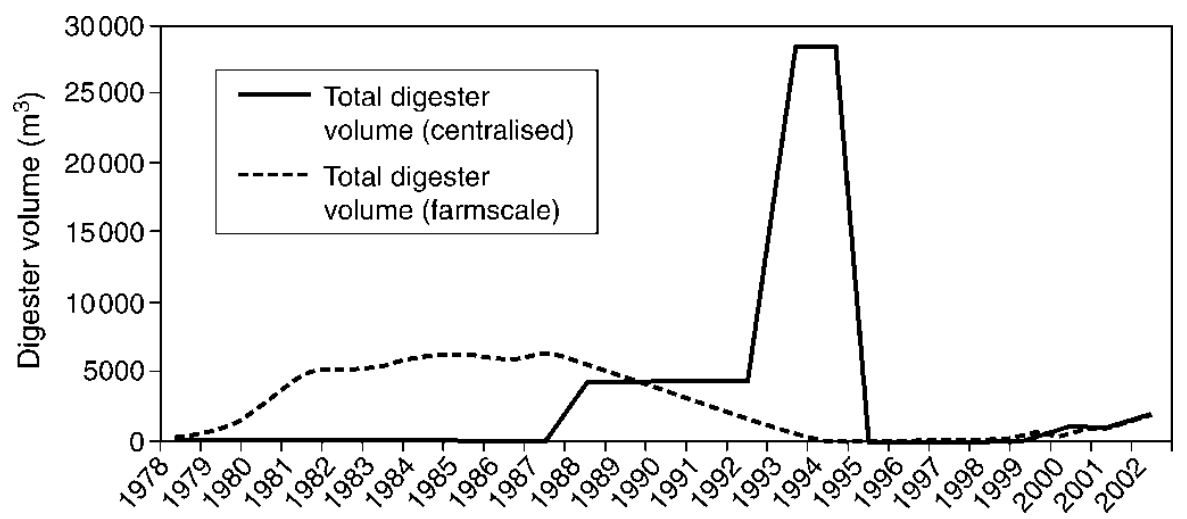

Figure 7. Accumulated digester capacity of Dutch farmscale and centralised biogas plants Source: Based on data in Raven (Ref. 9). 
international networks then existed for exchanging ideas and experiences. In 1976 Wageningen researchers began to investigate relationships between process parameters (temperature, time) and biogas yields. Part of the research project was the construction of a small pilot plant $\left(270 \mathrm{~m}^{3}\right)$, together with a pig farmer in Garderen (1979). Biogas was used for heating the farm and stable. ${ }^{17}$

The outcomes looked promising, leading to a three-year, follow-up research programme (1980-1983) of 2.8 million Dutch guilders (€1.3 million). The Ministry of Economic Affairs, responsible for energy policy, financed $60 \%$. Manure digestion was sponsored, because of the promise of cheap alternative energy production. Hence, the guiding principle was to optimise biogas yields. Investigations focused on the process's thermal conditions in relation to biogas yields. Farms were chosen on the basis of size and energy demand and economic performance was calculated on the basis of energy yields and savings. There was little attention for agricultural benefits like improved fertilizer characteristics. Driving actors in the emerging biogas field were researchers at the Institute for Mechanisation, Labour and Buildings (IMAG) and the Departments of Microbiology and Water Treatment, both from Wageningen Agricultural University. Farmers were also involved, not as passive users, but as active participants providing feedback or even co-developing plants with suppliers.

The programme set off a rapid increase in farmscale plants, to 26 in 1983. IMAG monitored the projects, acting as an intermediary actor who aggregated local outcomes and codified results in reports. The programme was successful in generating much technical knowledge. Researchers and technology suppliers learned detailed lessons about manure composition, microbiological processes inside the digester, relationships between temperature, processing time and biogas yields. They learned about advantages and disadvantages of components such as manure storage systems, manure pumps, gas engines, heat exchangers, cutters, mixers and separation technologies. Several components proved to be vulnerable. The pump that supplied manure often suffered from blockages, and mechanisms to stir manure inside the digester worked poorly and often broke down. Furthermore, monitoring showed that biogas contained small amounts of hydrogen sulphide, which damaged gas engines and transport pipes, because of its corrosive properties. A major disappointment was that biogas yields, and thus savings on energy costs, were lower than expected, in some plants $50 \%$ below expectations. All plants had a negative return on investment. ${ }^{18}$

As a result farmers' and researchers' expectations started to diverge. Farmers no longer expected biogas plants to become feasible in the short term, while researchers argued that technical breakdowns were teething problems, which they would solve in the future. Furthermore, 'repair work' was done with new expectations. In 1982, IMAG researchers promised future profitability because of expected rises in energy prices: ${ }^{19}$

The expectation is that energy prices will increase more rapidly than the costs of biogas plants. The result is that in the future, economic feasibility will increase. ... The value of $1 \mathrm{~m}^{3}$ biogas will also increase, due to the expected price increase of domestic fuel oil, and an estimated inflation rate of 5\%. For 1982, calculations use a value of 0.52 Dutch guilders; in 1983 the value will already be 0.552 Dutch guilders per $\mathrm{m}^{3}$ manure. In 1985 the value will be 0.615 Dutch guilders and in 1990 the value will be 0.812 Dutch guilders. ... if these calculations are continued, the value will be 1.608 Dutch guilders per $\mathrm{m}^{3}$ in 2000 ! 
As a second line of defence, expectations with a new content were formulated, arguing that economic feasibility could be improved with bigger, centralised biogas plants that benefited from economies of scale. But these promises were not immediately picked up.

\section{Decline of Farmscale Plants and Emergence of Centralised Plants (1986-1995)}

In 1986 global oil prices dropped rapidly in the energy regime, undermining previous expectations about future economic feasibility. The belief in farmscale plants rapidly declined and no new farmscale plants were built. At a meeting of the Dutch biogas community in 1986, a prominent researcher expressed the communis opinio as follows: ${ }^{20}$

Participants' attitudes towards manure digestion are fairly clear. If solely energy generation is considered, the application of manure digestion is not feasible at this time. Neither is improved feasibility likely in the short term. The optimal biogas yields from manure are known, and we cannot foster high expectations about rising gas production from manure.

At the same time, developments in the agricultural regime created a window of opportunity for centralised biogas plants. Earlier promises about these plants were now picked up and became linked to increasing mineral and manure problems. Between 1950 and 1980, the number of animals increased rapidly, as part of specialisation processes and increasing farm sizes in Dutch agriculture (Figure 8).

The rapid growth of artificial fertilizer use and the application of feeding concentrates with high mineral content resulted in huge problems with manure and mineral surpluses. ${ }^{21}$ Dutch manure problems were the worst in Europe, because too much manure was spread over small surface areas. In 1984, a new Minister of Agriculture enacted a temporary law that prohibited the establishment of new farms, followed by two permanent laws in 1987: one for soil protection and one for manure bookkeeping and distribution. In response to manure problems, policy makers stimulated three options: (a) process manure and export the product; (b) distribute unprocessed manure within the Netherlands from regions with a manure surplus to regions with a manure shortage; (c) reduce the supply of minerals into the agricultural system by changing the composition of animal feed. Centralised manure processing was seen as most promising by several regime actors. Within this general option manure digestion was one sub-option

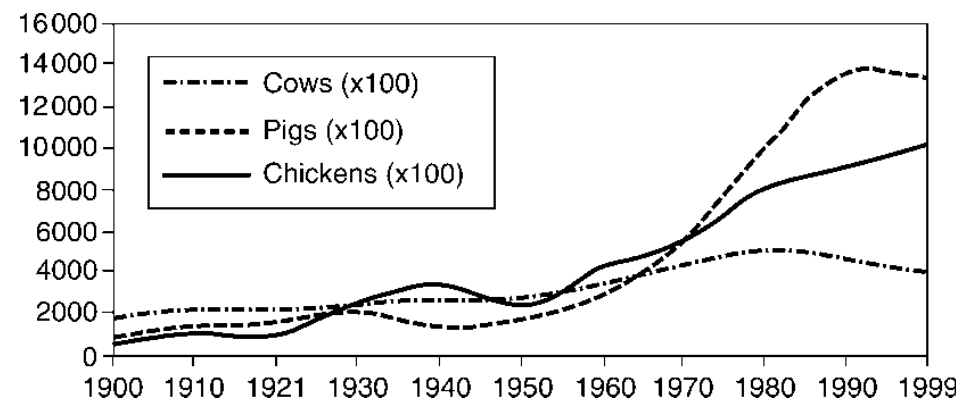

Figure 8. Number of Dutch cows, chickens and pigs Source: Based on data in Raven (Ref. 9). 
that co-existed and competed with other sub-options, e.g. drying manure, separating manure into different fractions. Although manure digestion did not reduce the amount of minerals in the manure, it stabilised manure for further processing. Several regime actors developed the vision to produce fertilizer granules that could be exported to southern European markets. This vision legitimated the construction of a huge centralised digestion plant (Promest BV). In this vision the functionality of manure digestion was no longer linked to energy production but to manure processing. A second, very different centralised plant was constructed in Deersum.

The Promest BV company was established in 1986, supported by a network that was dominated by established agricultural branch organisations, agricultural policy makers, chemical companies and financial companies (Rabobank, Interpolis). Research institutes (IMAG, TNO and Wageningen Agricultural University) were involved, but no longer as dominant actors. The plant's reactor size $\left(4000 \mathrm{~m}^{3}\right)$ was about 15 times larger than the average farmscale digester, and designed to process 100,000 tons of manure annually. The plant design also used various new technologies, some of which came from the chemical and food industries. Initial construction costs were high: 23 million guilders (€10 million), but Promest's product champions made optimistic claims about future profitability to keep up with other competing options, in particular the distribution of unprocessed manure. Researchers doubted the figures, but they were ignored.

Because the plant represented a non-linearity with past experiences, technology suppliers engaged in international cooperation. A German company supplied the digesters, and Promest exchanged ideas with similar companies in Denmark. Promest adopted an innovative design, dividing the digestion process into two steps (two-phase digester). The first digester tank $\left(1000 \mathrm{~m}^{3}\right)$ would capture most of the hydrogen sulphide, while the second tank $\left(1000 \mathrm{~m}^{3}\right)$ would produce clean biogas. This design was expected to reduce purification costs, because a purification step was no longer needed. The design also included a third, conventional digester $\left(2000 \mathrm{~m}^{3}\right)$. The produced biogas could be used for reducing the overall plant's energy demand. The manure leaving the digesters was processed into a solid fraction, which was mixed, dried and palletised, resulting in the main product: fertilizer granules.

The plant began operation in 1988, but soon experienced difficulties. The heat exchangers did not heat the manure sufficiently inside the digester tank. The chopper that cut large parts into smaller parts (e.g. straw) got stuck. An unexpected scum layer was formed inside the digester, causing blockages. Although anti-scum substances existed, they were very expensive. The innovative two-phase digester design did not produce the expected results, and the biogas leaving the second digester still contained high levels of hydrogen sulphide. Hence, it was necessary to install an (expensive) caustic bath. Promest also learned that the resulting granules were chemically unstable and could spontaneously burst into flames, something that happened in 1992 in transport to Spain and Portugal. Also the marketing of granules was difficult, because of southern European farmers' unfamiliarity with the product. Hence, sales were low.

Despite technical and economic problems, a plan was made in 1990, supported by agricultural policy makers and branch organisations, to expand the factory with a new plant that would increase capacity from 100,000 to 600,000 tons of manure per year. Some actors in the local network warned against this plan, but the pressure to solve manure problems overshadowed them. Seven new digesters were installed, increasing total 
investment costs to more than 100 million Dutch guilders (€5 million), $40 \%$ of which came from investment grants from the Ministry of Agriculture. In 1993 the new plant opened, but it was soon apparent that the plant operation remained problematic with regard to: (a) technical design of digester tanks, separation technologies and dryers, (b) process conditions and operating characteristics, (c) marketing channels and user demands, (d) sufficient and reliable manure supply. Economic losses sky-rocketed and the plant was shut down in late $1994 .^{22}$ This big and costly failure led to very negative expectations about manure digestion and withdrawal of support and resources. This coincided with the failure of the second, centralised biogas plant.

Deersum, a small village of 115 inhabitants, encountered problems with the sewer system. These problems gave rise to discussions in the early 1980s that eventually resulted in a plan for self-generation of electricity, using a wind turbine and a centralised biogas plant. ${ }^{23}$ The European Commission, the Ministry of Environment and the Province of Friesland helped finance the biogas project. Compared to the Promest project, the Deersum plant contained more continuation of previous farmscale plant developments. The plant supplier and the research institute involved in the project had also worked with biogas plants in the early 1980s. Also technical expectations were hardly changed and the design was similar to older biogas plants. The centralised plant was small $\left(210 \mathrm{~m}^{3}\right)$, with seven farmers supplying manure. Construction started in 1986 and operation in 1988.

Several technical problems appeared. Pumps, desulphurisation boxes and the generator needed modification or replacement. The digester suffered problems from the formation of a scum layer. Pressing problems were solved during the first year, but frequent repairs remained necessary. Biogas yields were half of what was expected, resulting in high electricity production costs in the first year (1.5 Dutch guilders per $\mathrm{kWh}$ compared to 0.18 Dutch guilders for normal electricity). Evaluations indicated that future electricity production costs would probably remain higher than normal electricity prices. Nevertheless, Deersum farmers continued the biogas plant until 1995. The main reason was that a good learning process changed the content of their expectations. These expectations were about plant functionality rather than technical design. While the initial idea was to produce renewable energy, farmers gradually learned about additional advantages, in particular the benefits of centralised manure storage, the possibility of reducing artificial fertilizer use and easier handling of digested manure. Furthermore, the research institute learned from visits to Denmark that biogas yields could be substantially improved through adding organic waste (co-digestion). When Deersum farmers wanted to introduce co-digestion in 1995, they faced opposition from the Province of Friesland. The Province had just invested in a new collection and processing infrastructure for household waste and opposed the use of this waste for co-digestion. This was the deathblow for Deersum farmers, who lost the will to overcome technical and economic barriers.

So by 1995 Dutch biogas development had ground to a halt. Failed projects and disappointing learning processes resulted in negative expectations about manure digestion. Supporting networks and resources dried up.

\section{Difficult Revival (1995-2003)}

Between 1995 and 1998 no biogas plants were constructed, although some universities maintained a level of desk-research, using information from foreign projects. Especially 
in Germany and Denmark, ${ }^{24}$ several improvements were made in the mid 1990s, improving technical, environmental and agricultural performance. It was learned that:

- biogas yields could be increased through co-digestion, i.e. the addition of organic waste to manure digestion;

- hydrogen sulphide contaminations could be removed with a new, inexpensive biological purification system;

- processed manure was more homogeneous, which facilitated fertilizer application;

- processed manure could be easier absorbed by crops, because minerals are no longer attached to organic matter. Hence artificial fertilizer use could be reduced;

- processed manure had less pathogens and weeds, when digestion occurred at high temperatures;

- the collection and use of methane reduced greenhouse gas emissions.

So Dutch advocates of biogas plants, especially research institutes, consultancies and small technology suppliers, developed new expectations about the technical design and parameters of biogas plants. They pointed to the positive learning processes to attract new attention and support. In addition, the advocates also developed new expectations about functionality. While previous visions had focused on single functionalities (energy generation, reduced manure problems), the advocates now developed new promises about multi-functionality of manure digestion: (a) biogas could make agriculture more sustainable by reducing artificial fertilizer use, (b) biogas could reduce methane emissions, a strong climate-forcing gas, and (c) biogas could produce renewable energy. However, the new promises were not immediately shared by everyone. Agricultural regime actors and policy makers were especially reluctant, because previous disappointments were followed by strongly negative beliefs.

Developments in the electricity and agricultural regimes created new windows of opportunity. In the energy regime, climate change came to be seen as major problem. In response, electricity companies developed a new marketing concept: 'green electricity', generated from renewable sources. From 1996 to 2002 the government stimulated green electricity with demand-side subsidies, resulting in increasing interest from consumers (25,000 in $1997 ; 225,000$ in $1998 ; 700,000$ in 2000, and 1,000,000 in 2000). This market growth stimulated energy companies to explore a range of renewable energy options, including manure digestion. In the agricultural regime, manure and mineral problems became less prominent, because of the success of other options than manure digestion, especially the distribution of unprocessed manure. A national manure distribution system was set up, spreading minerals more evenly. Furthermore, the number of pigs and cows began to drop (Figure 8), as a result of stronger international competition and decreasing subsidies from Brussels. Methane emissions in agriculture became a new problem, related to climate change. Following the 1997 Kyoto protocol, the Ministry of the Environment developed a climate policy (1999) that also focused on the reduction of methane emissions, a strong climate-forcing gas. A research programme (ROB) with $€ 200$ million was established to explore and develop options to reduce greenhouse gases other than carbon dioxide.

Both regime developments led to new resources and interest from powerful actors in manure digestion, and in the late 1990s new projects emerged. Technological improvements abroad and new visions of multi-functionality helped legitimate that manure 
digestion had better chances now. The social network that supported and carried the projects was diverse, including energy companies, local farmers, agricultural organisations, manure distribution companies, researchers, technology suppliers and the Ministry of Environment. It was a problem that much knowledge had been lost in previous years without practical activity. Existing companies, such as the Wolter en Dros company, and new companies, such as Biorek Agro, Ecogas and Biogas Nederland, tried to build up new expertise, in cooperation with German or Danish firms and industries or with university research groups. ${ }^{25}$ Between 1998 and 2003, two new centralised biogas plants and four farmscale plants were constructed.

Multi-functionality formed the driving vision behind the two centralised plants. Electricity companies were involved in the projects, because of their interest in renewable energy (Eneco in Elsendrop, Essent in Nijverdal). Manure distribution companies were involved, because of their interest in agricultural benefits of processed manure and reduction of methane emissions (Mestac in Elsendrop, Verkooijen in Nijverdal). Both projects showed that technical performance of manure digestion had indeed improved. The new, biological purification system efficiently removed hydrogen sulphide and codigestion substantially improved biogas yields and incomes from energy sales, but processing manure proved more difficult. The transformation of the wet manure slurry into a dry, homogeneous and manageable product required complicated separation techniques, e.g. centrifugation to create a liquid and solid fraction, reversed osmosis and an ultrafilter to further clean the liquid fraction. The reversed osmosis unit and ultra-filter suffered especially from blockages and breakdowns. Despite these problems in processing, the projects showed that processed manure had indeed agricultural benefits. So, functional expectations were met, but technical expectations were not. It is unsure at this moment whether the benefits outweigh the problems. So the multi-functionality vision of centralised plants is under pressure. Nevertheless, renewable energy and reduced methane emissions still provide sufficient incentives.

Farmscale plants were mainly built for reasons of renewable energy generation, which provided additional income for the farmer. With less attention to manure processing, complicated separation technologies were not needed. Performance of the farmscale plants was good. Based on a German design, the Denekamp plant produced more biogas than expected: about $26 \mathrm{~m}^{3}$ biogas per $\mathrm{m}^{3}$ manure, compared with $13-15 \mathrm{~m}^{3}$ biogas per $\mathrm{m}^{3}$ manure in the 1980s. Subsequently, three projects were sponsored (Sterksel, Hengelo, Goutem) on experimental farms to: (a) better understand the process parameters, (b) further explore co-digestion, (c) explore economic feasibility. All projects showed good technical performance and biogas yields that were equal or higher than expected.

Although technical plant performance was much better, other severe barriers existed. Although both farmscale and centralised projects showed that co-digestion with organic waste was necessary to boost biogas yield and economic feasibility, regulatory confusion hindered its adoption. No policy existed for adding organic waste to manure streams, resulting in long delays in permit procedures. An ad-hoc policy decision in 2000 allowed the construction of biogas plants that used co-digestion, but project developers had to show a sample of the end product, before they could receive a permanent permit. This strange procedure created uncertainty for investors. Local problems with permits were collected, compared and aggregated in reports by lobby groups to put pressure on the Minister of Agriculture. These groups also organised meetings and conferences where farmers and researchers discussed problems with representatives from the Ministry. 
Eventually the Minister created a list of organic waste substances that could be used without a permit.

A second barrier was related to the Dutch financing scheme of renewable energy (REB), which was based on tax exemptions for users of green electricity. Investers perceived this demand-side scheme as uncertain and too dependent on changing political preference. The uncertainty frustrated renewable energy investments in general, including manure digestion. In 2003, the REB scheme was indeed replaced by a new scheme, which stimulated the production of renewable energy for a guaranteed period of 10 years, thus creating long-term certainty for investors.

The removal of these barriers created a new wave of expectations about future markets for biogas plants. In 2003 and 2004 several new projects were started and more applications are in the pipeline.

\section{Conclusions}

The case study showed clear ups and downs and non-linearity in Dutch development of manure digestion. Combining the literature on expectations and niche development, a perspective that explained non-linearity through the interaction of learning processes, network building and articulation of expectations was described. In this perspective, local projects functioned as important locus for these processes, outcomes of which required dedicated aggregation work to link back to global networks and rules. The case study clearly showed the importance of local projects. It should be noted, however, that biogas plants are a configurational technology, where the challenge is to get multiple components to work together. Fleck argued that for such configurational technologies, local implementations are crucial to facilitate the process of 'learning by trying'. He argued that 'over a number of successful instances of implementation, local knowledge becomes gradually absorbed into generic knowledge'. ${ }^{26}$ So, while local projects were indeed crucial for learning processes in biogas development, they may be less prominent for other technologies.

With regard to non-linearity we draw the following conclusions about the usefulness of the niche development perspective. First, the upswings in development are well explained through the interaction between positive outcomes, learning processes, expectations that link technology to a functional application, and the support from social networks. In the first period, positive outcomes from the initial farmscale project (Garderen, 1979) led to positive expectations, a follow-up research programme, more projects and the emergence of a biogas community. Also in the second period, these processes explain the upswing: previous learning processes showed that economic feasibility was only possible in larger, centralised plants; there was a vision that digestion could help solve manure problems and export fertilizer granules abroad (although that vision was contested by advocates of other options); and there was a network of powerful actors (agricultural branch organisations pushed by policy makers). In the upswing of the third period, one could point to learning processes abroad; there was a vision that multi-functional biogas plants could both generate renewable energy and improve manure quality, and actors expected that the new technical designs would perform better; and there was a diverse network of supportive actors. In all three periods, the interaction between the three processes was behind the upswing. It should be noted, however, that the niche-expectation about functionality was often linked to external regime problems (high energy prices in 
the first period; major manure problems in the second period; climate change, methane emissions and green electricity in the third period). Another qualification is that upscaling in the Promest centralised plant (1990-1994) still occurred in the face of negative results. In this instance, the shared expectation and support from agricultural regime actors were stronger than previous negative results and warnings from local actors.

Second, downswings can also be explained with the interaction of niche-internal processes. When learning processes produce outcomes that do not meet the expectations, this leads to a backlash in expectations that turn from positive to negative. When actors' beliefs turn sour, networks fall apart and resources are reduced, leading to a decline in development. This happened to farmscale plants in the early 1980s, when biogas yields were lower than expected. Initially, the niche was kept alive through 'repair work' in expectations, promising future economic feasibility if energy prices continued to increase. However, an external regime development (the decline in energy prices in 1986) undermined this promise, followed by a downswing in farmscale plants. An even more dramatic downswing occurred in the second period when the huge, centralised Promest plant failed in late 1994. Because expectations and investments were high, the backlash was so strong that beliefs in manure digestion were dead for several years after. External developments (the decreasing number of animals and successful development of other options) reinforced this belief. This need not have happened, because there were warnings from local actors, based on negative outcomes from previous learning processes. These warnings were neglected, because agricultural branch organisations were under high political and societal pressure to promise solutions for manure problems. Hence a 'breakthrough approach' was followed instead of a 'bricolage approach', with similar negative outcomes as the American breakthrough approach in wind turbines. ${ }^{27}$

Third, non-linearity and change in direction of developments are related to a change in the content of expectations, especially new visions on functionality. These visions changed from energy saving in the first period to manure processing in the second period to multi-functionality in the third period (renewable energy, reduction methane emissions, improved manure quality). These changed functional visions led to new search heuristics that altered the direction of learning processes and technical trajectories. One explanation of these changes in expectations is the interaction with nicheinternal processes. When learning processes produce negative outcomes, actors engage in repair work through formulating new expectations. This happened with farmscale plants in the early 1980s, when learning about poor economic feasibility led to new promises about better economic performance of bigger centralised plants. It happened in the late 1990s, when learning processes abroad were used by product champions to formulate new promises about technical performance and multi-functional biogas plants. In both instances, learning processes are not sufficient to explain the change in functional expectations. An additional, second explanation is the importance of external developments: regime problems. Local promises, based on local learning processes, are translated into a global niche-expectation when they become linked to external regime problems. The promises about centralised plants became a global niche-expectation when they became linked to manure problems in the agricultural regime. The promises about multi-functional biogas plants were picked up more widely, when they became linked to green electricity markets, methane emissions and environmental problems. Also competition with other options changed expectations: the product champions of 


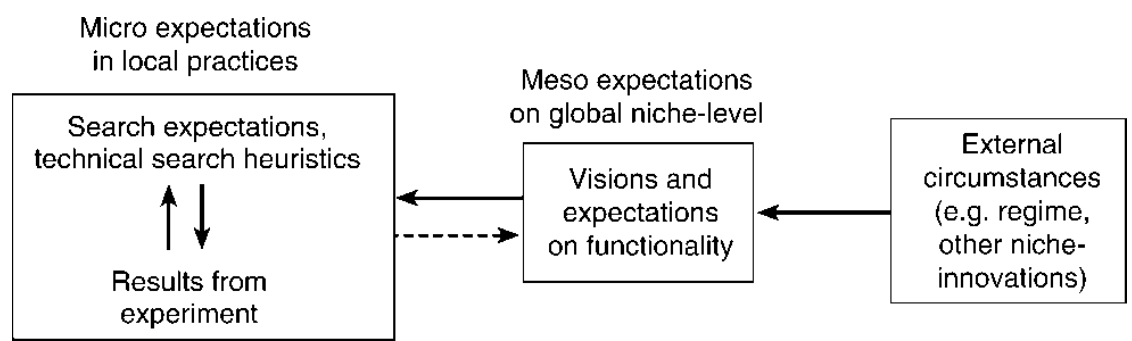

Figure 9. Relationships between levels of expectations Source: Raven (Ref. 9, p. 51).

the Promest plant promised dramatic reductions of process costs to compete with other solutions to the manure problem.

In sum, we conclude that the proposed niche development perspective (with interactions between expectations, learning processes and network building) gives a good explanation of ups and downs in the biogas innovation journey, but the niche perspective is not sufficient, because it only highlights internal niche processes. For a complete understanding of non-linearity and changes in expectations, we need to include external (regime and competitive niche) developments. This can be done, using Van Lente's intuitions about different levels of expectations. ${ }^{28}$ At the local level, search expectations are important to guide local learning processes for solving specific technical problems. At the global niche-level, visions and expectations about functionality are important. These visions result in functional requirements and a protected space for local activities and projects. Based on our conclusions, we add that functional niche expectations may also change because of external circumstances. The bold and dotted lines in Figure 9 summarise this. For the case study we conclude that changes in the content of niche expectations were caused more by the influence of external regime developments than by feedback from learning processes in local projects. Nevertheless, local learning processes played some role, in the sense that they legitimated that developments were going in the right direction.

This analytical scheme can be generalised, but our specific conclusion on the relative importance of local learning processes and external developments holds mainly for this case. In our analysis of manure digestion in Denmark, we found that the importance of external developments and learning processes was more equal. ${ }^{29}$ In Denmark, there were also ups and downs in farmscale and centralised plants, but with less of a hype and backlash character. Learning processes were more gradual and cumulative. When outcomes were disappointing, local projects still continued on a small scale, while in the Netherlands everything came to a stop. In the Danish case there was also more attention for circulation of knowledge and dedicated aggregation to translate local lessons to the global niche level. So it seems that the strength of the link between local practices and global niche expectations depends on dedicated activities and network structures.

\section{Acknowledgements}

We want to thank Kornelia Konrad and two anonymous referees for their useful comments on previous versions of this paper. We gratefully acknowledge financial support from the Dutch Knowledge network on System Innovation (KSI). 


\section{Notes and References}

1. G. Dosi, Technological paradigms and technological trajectories: a suggested interpretation of the determinants and directions of technical change, Research Policy, 6, 1982, pp. 147-162; R. R. Nelson \& S. G. Winter, An Evolutionary Theory of Economic Change (Cambridge, MA, Bellknap Press, 1982).

2. W. E. Bijker, Of Bicycles, Bakelites and Bulbs: Towards a Theory of Sociotechnical Change (Cambridge, MA, MIT Press, 1995).

3. H. Van Lente \& A. Rip, Expectations in technological developments: an example of prospective structures to be filled in by agency, in: C. Disco and B. J. R. van der Meulen (Eds) Getting New Technologies Together (Berlin, Walter de Gruyter, 1998), pp. 195-220.

4. D. MacKenzie, Economic and sociological explanations of technical change, in: R. Coombs, P. Saviotti \& V. Walsh (Eds) Technological Change and Company Strategies: Economic and Sociological Perspectives (London, Academic Press, 1992), pp. 25-48, see p. 32.

5. H. Van Lente, Promising Technology: The Dynamics of Expectations in Technological Development (Delft, Eburon, 1993).

6. J. Schot, R. Hoogma \& B. Elzen, Strategies for shifting technological systems. The case of the automobile system, Futures, 26, 1994, pp. 1060-1076; R. Kemp, J. Schot \& R. Hoogma, Regime shifts to sustainability through processes of niche formation: the approach of strategic niche management, Technology Analysis and Strategic Management, 10, 1998, pp. 175-196; R. Hoogma, R. Kemp, J. Schot \& B. Truffer, Experimenting for Sustainable Transport: The Approach of Strategic Niche Management (London, Spon Press, 2002).

7. H. Van Lente, op cit., Ref. 5; Van Lente \& Rip, op cit. Ref 3.; N. Brown \& M. Michael, The sociology of expectations: retrospecting prospects and prospecting retrospects, Technology Analysis \& Strategic Management, 15, 2003, pp. 3-18.

8. Hoogma et al., op cit., Ref. 6.

9. R. Hoogma, Exploiting technological niches: strategies for experimental introduction of electric vehicles, PhD thesis, University of Twente, 2000; B. Van Mierlo, Kiem van maatschappelijke verandering: verspreiding van zonnecelsystemen in de woningbouw met behulp van pilot projecten, PhD thesis, Amsterdam, the Netherlands Aksant, 2002; R. P. J. M. Raven, Strategic niche management for biomass, PhD thesis, Eindhoven University of Technology, 2005.

10. J. Law \& M. Callon, The life and death of an aircraft: a network analysis of technical change, in: W. E. Bijker and J. Law (Eds) Shaping Technology/Building Society: Studies in Sociotechnical Change (Cambridge, MA, MIT Press, 1992), pp. 21-52.

11. M. Hård, Technology as practice: local and global closure processes in diesel-engine design, Social Studies of Science, 24, 1991 pp. 549-585; C. Disco \& B. Van der Meulen, Getting case studies together: conclusions on the coordination of sociotechnical order, in: C. Disco \& B. Van der Meulen (Eds) Getting New Technologies Together: Studies in the Making of Sociotechnical Order (Berlin, Walter de Gruyter, 1998), pp. 323-351; J. J. Deuten, Cosmopolitanising Technology: A Study of Four Emerging Technological Regimes (Enschede, Twente University Press, 2003).

12. This phrase comes from Arie Rip (private communication).

13. See Deuten, op cit., Ref. 11; F. W. Geels \& J. J. Deuten, Local and global dynamics in technological development: a socio-cognitive perspective on knowledge flows and lessons from reinforced concrete, Science and Public Policy, 33(4), 2006, pp. 265-275.

14. Note that Figure 4 not only contains cognitive rules, but also formal and normative rules. Formal rules refer to regulations, standards and formal institutions; normative rules refer to role relationships in networks and behavioural norms. For a more elaborate discussion of these rules see F. W. Geels, From sectoral systems of innovation to socio-technical systems: insights about dynamics and change from sociology and institutional theory, Research Policy, 33, 2004, pp. 897-920.

15. K. B. Clark, The interaction of design hierarchies and market concepts in technological evolution, Research Policy, 14, 1985, pp. 235-251.

16. Raven, op cit., Ref. 9.

17. H. R. Poelma, Ervaringen met biogasinstallaties op praktijkbedrijven (Wageningen, IMAG, 1987).

18. P. Hoeksma, Biogaswinning en- benutting op veebedrijven (Wageningen, IMAG, 1984).

19. Werkgroep Bedrijfsopzetten Biogasinstallaties, Biogas op Veebedrijven. Toepassingsmogelijkheden en Perspectieven (Wageningen, IMAG, 1982).

20. A. F. M. van Velsen, Biogas uit Mest: Hoe Verder na 1986 (Nijmegen, Haskoning, 1986). 
21. R. P. J. M. Raven \& G. P. J. Verbong, Ruling out innovations, Innovation: Management, Policy \& Practice, 6, 2004, pp. 178-198.

22. F. Bloemendaal, Het Mestmoeras (The Hague, SDU uitgevers, 1995).

23. J. Paques, Haalbaarheidsstduie Energieplan Deersum (The Hague, Ministry of Spatial Planning, Housing and Environment, 1982).

24. For a detailed analysis of manure digestion in Denmark see F. W. Geels \& R. P. J. M. Raven, Coevolutionary dynamics in system innovations and transitions to sustainability: a multi-level analysis of biogas in Denmark (1970-2002), International Journal of Sustainable Development and World Ecology, (forthcoming, 2006). See also R. P. J. M. Raven, Biogas plants in Denmark: successes and setbacks, Renewable and Sustainable Energy Reviews, (forthcoming 2006).

25. Biorek Agro was a joint venture between the Dutch manure distribution organisation (Mestac) and a Danish supplier of biogas plants (Bioscan). Ecogas and Biogas cooperated with German suppliers. Ecogas was a joint venture between Biomass Technology Group from Twente University and Wiefferink, a diversifying company strong in storage systems, such as silos. Biogas was a daughter company of the German firm Krieg \& Fischer Ingenieure GmbH.

26. J. Fleck, Learning by trying: the implementation of configurational technology, Research Policy, 23, 1994, pp. 637-652, see p. 642. The importance of local learning processes for biogas plants is shown in M. Junginger, E. de Visser, K. Hjort-Gregersen, J. Koornneef, R. P. J. M. Raven, A. Faaij \& W. Turkenburg, Technological learning in bioenergy systems, Energy Policy (forthcoming 2006).

27. R. Garud \& P. Karnøe, Bricolage versus breakthrough: distributed and embedded agency in technological entrepreneurship, Research Policy, 32, 2003, pp. 277-300.

28. Van Lente, op. cit., Ref. 5, pp. 66-70.

29. See Geels \& Raven, op. cit., Ref. 24. 